\title{
ONDE ESTÁ O DÉFICIT? - POLÊMICA EM TORNO DA DISLEXIA
}

\author{
PATRICIA AQUINO \\ $(\mathrm{UNICAMP})^{1}$
}

\begin{abstract}
RESUMO: Neste texto, apresento o resumo da gênese da polêmica em torno daquilo que alguns chamam "dislexia" e analiso enunciados e materiais produzidos por profissionais que, embora se digam especialistas em alfabetização, não têm formação linguística adequada para acompanhar e alfabetizar crianças consideradas ou não disléxicas. Na sequência, apresento algumas razões linguísticas para os erros ortográficos e analiso um dado do acompanhamento de uma criança em processo de aquisição de leitura e escrita no Centro de Convivência de Linguagens (CCazinho), do IEL/Unicamp, fundamentado no trabalho realizado por Coudry (1986/1988). Esse percurso tem o objetivo de argumentar que o déficit não está nas crianças diagnosticadas como disléxicas ou portadoras de outros problemas, mas na formação inadequada dos profissionais que estão "tratando" de dificuldades de leitura e de escrita. Palavras-chave: dificuldades escolares; dislexia; polêmica, formação de professores
\end{abstract}

RESUMEN: En este texto, presento el resumen de la génesis de la polémica sobre aquello que a algunos les ocurre llamar "dislexia" y analiso afirmaciones y materiales producidos por profesionales que, aunque se declaren especialistas en alfabetización, no tienen conocimiento linguístico adecuado para acompañar y alfabetizar a los niños considerados o no disléxicos. Después, presento algunas razones linguísticas para los errores ortográficos y analiso un dato del acompañamiento de un niño en el proceso de adquisición de lectura y de escritura en el Centro de Convivência de Linguagens (CCazinho), de IEL/Unicamp, basandome en el trabajo de Coudry (1986/1988). Ese trayecto tiene el objetivo de argumentar que el déficit no está en los niños que ricibieron el diagnóstico de dislexia o de otros problemas, sino en la formación inadecuada de profesionales que "tratan" de dificultades de lectura y de escritura.

Palabras-llave: dificultades escolares; dislexia; polémica; formación de profesores.

\section{INTRODUÇÃO}

Algumas obras foram cruciais para que eu desenvolvesse a tese defendida em 2016², dentre elas Diário de Narciso, de Coudry ([1986]1988). A teorização sobre as afasias me estimulou ${ }^{3}$ a analisar materiais que dão suporte à alfabetização,

${ }^{1}$ Docente do Centro de Ensino de Línguas (CEL)/UNICAMP. Email: patdeaquino@gmail.com

${ }^{2}$ Tomei por base, neste texto, algumas reflexões realizadas em minha tese Polêmica em torno de dislexia: um caso de interincompreensão, orientada pelo Prof. Dr. Sirio Possenti e financiada pela Fapesp (Processo 2013/009985-0).

${ }^{3} \mathrm{O}$ estímulo produzido em mim pelas leituras de Diário de Narciso - uma obra pioneira não só pelo tema, mas por seu estilo - me levou a escrever este texto na primeira pessoa do singular. Em alguns momentos, deixo transparecer uma indignação sobre os fatos relatados que, a meu ver, também aparece no livro de Coudry. 
a diagnósticos e a tratamentos de dislexia. O contato com a Neurolinguística Discursiva (doravante ND) também me estimulou a acompanhar a aquisição da leitura e da escrita por uma criança com dificuldades escolares de leitura e escrita para melhor empreender uma discussão em torno daquilo que tem sido denominado, em diversos campos, como dislexia.

Antes de apresentar a análise de parte de um material que foi desenvolvido para a alfabetização, resumo a história da dislexia e, em seguida, a gênese da polêmica em torno do tema, pois considero essas questões como pano de fundo muito relevante para a argumentação que desenvolvo ao longo do texto para responder à pergunta: “Onde está o déficit?". Veremos que o primeiro enunciado em que há a afirmação de que a dificuldade de leitura e escrita seria congênita polêmica até hoje - foi questionado logo após ter sido enunciada.

\section{BREVE HISTÓRIA DA DISLEXIA}

Segundo vários autores, por exemplo o psiquiatra e educador francês Ajuriaguerra (1984), o que muitos chamam de dislexia (dislexia congênita, atualmente conhecida também como dislexia específica de evolução ou dislexia do desenvolvimento) tornou-se uma questão a partir do trabalho de Hinshelwood ([1896]1900), embora tenha sido o texto "Um caso de cegueira verbal congênita", publicado por Morgan em 1896, o primeiro a tratar da questão. Este texto é fundamental por dois motivos: a) contém o primeiro relato de caso publicado de um sujeito - não adulto e sem lesão - acometido pela então chamada "cegueira verbal congênita" e b) contém a primeira atribuição do caráter congênito à dislexia que, como veremos, tem papel crucial na polêmica em torno da sua existência.

Antes da publicação de Morgan (1986), a dislexia, termo cunhado por Berlin, um médico oftalmologista alemão, era considerada na área médica como um comprometimento da capacidade de leitura de adultos previamente alfabetizados, decorrente de uma lesão cerebral, localizada especificamente na circunvolução de Broca, na vizinhança da fissura de Sílvio. Segundo Berger (1892), essa hipótese de Berlin foi confirmada em uma autópsia.

Berlin relatou também casos de pacientes que apresentaram dislexia não provocada por lesão. Segundo Hinshelwood ([1896]1900), a conclusão a que havia chegado o oftalmologista alemão foi a de que essa dislexia sem lesão era provocada pela ingestão de bebidas alcoólicas e sempre vinha acompanhada de outros sintomas, como perda da capacidade de localizar-se em um local conhecido e perda das habilidades manuais rotineiras, ambas decorrentes de um estado de confusão mental. Depois de um tempo de abstinência alcoólica, todos os sintomas desapareciam.

Em 1896, Morgan apresentou o caso de um adolescente de 14 anos que não correspondia aos casos relatados por Berlin. Nas palavras de Morgan, o caso é "bastante interessante, único, tanto que eu saiba, na medida em que ocorre sem lesão nem doença, mas é evidentemente congênito, e devido muito provavelmente ao desenvolvimento defeituoso daquela região do cérebro, que nos adultos produz 
praticamente os mesmos sintomas - isto é o giro angular esquerdo" (MORGAN, 1896, p. 1379) ${ }^{4}$.

Ao afirmar que "o caso ocorre sem lesão nem doença", Morgan descarta os fatores até então considerados como causas da dislexia nos adultos e, ao que tudo indica, por dedução, afirma que é "evidentemente congênito". Além disso, acrescenta a hipótese da existência de um provável "desenvolvimento defeituoso" de uma região específica do cérebro: "o giro angular esquerdo". Como se sabe, à época, não havia meios de verificar o cérebro de pacientes vivos; apenas nas autópsias podia-se confirmar ou não uma hipótese sobre a localização de uma lesão ou de um desenvolvimento defeituoso. Diferentemente da hipótese de Berlin, corroborada em autópsia, não há registros de confirmação ou rejeição da hipótese de Morgan, o que sugere que não foi realizada autópsia do sujeito por ele analisado ${ }^{5}$. Num segundo trecho da mesma página, o autor volta a afirmar que “essa inabilidade (para aprender a ler) é tão notável, e tão pronunciada, que eu não tenho dúvida de que é devida a algum defeito congênito.” (MORGAN, 1896, p. 1379).

Dessa vez, Morgan substitui o "é evidentemente” por “eu não tenho dúvida”, reafirmando sua crença de que a dificuldade de leitura do adolescente em questão é causada por um defeito congênito.

\section{POLÊMICA DESDE SEMPRE}

Hinshelwood inicia o capítulo 2 do livro Congenital Word-Blindness (Cegueira verbal congênita), publicado em 1917, deixando claro que demorou para utilizar o termo "dislexia" (segundo ele, já utilizado por outros autores), a fim de evitar o que chama de "ambiguidades e vaguezas que caracterizam muitos relatos recentes desse distúrbio" (Hinshelwood, 1917, p. 41). O autor insiste que, apenas a partir do conhecimento aprofundado da cegueira verbal adquirida e dos detalhes do funcionamento normal do cérebro, se poderia compreender a cegueira verbal congênita. É devido à necessidade desse conhecimento que ele justifica o fato de não ter voltado a escrever sobre o tema desde 1895, quando publicou o artigo Word-blindness and visual memory (Cegueira visual e memória visual) o qual, embora contivesse exclusivamente análises de pacientes adultos, teria inspirado Morgan a analisar o caso do adolescente por ele acompanhado, em 1896.

Hinshelwood conta aos seus leitores que Morgan lhe enviou uma carta, junto com uma cópia do referido artigo publicado, na qual deixava claro que foi o texto de Hinshelwood de 1895 que chamou sua atenção para a cegueira verbal congênita. Na sequência, Hinshelwood critica o fato de Morgan, por falta de conhecimento

\footnotetext{
${ }^{4}$ Esta e outras citações, além de contribuírem para a fundamentação teórica deste artigo, são, conforme o leitor poderá perceber, objeto de análise no interior do discurso polêmico em torno da dislexia.

${ }^{5}$ Atualmente, exames (genéticos e de neuroimagem) têm sido realizados para descobrir a causa da dislexia, mas de tempos em tempos uma nova causa é "finalmente descoberta", conforme detalhado em Aquino (2016).
} 
necessário sobre a cegueira verbal, não ter analisado e explicado devidamente os sintomas. O autor critica ainda o fato de Morgan ter utilizado determinadas expressões, inadequadas, segundo aquele, em um texto científico. A primeira delas foi "em sua opinião" ${ }^{6}$ ", usada para afirmar que se tratava de um caso de cegueira verbal. $\mathrm{O}$ autor cita um trecho de Morgan para indicar outras expressões que julgava incompatíveis com o rigor científico: "evidentemente congênito, e devido muito provavelmente ao desenvolvimento defeituoso daquela região do cérebro, que nos adultos produz praticamente os mesmos sintomas - isto é, o giro angular esquerdo.” (HINSHELWOOD, 1917, p. 42, grifos da autora).

Apesar de tecer essas severas críticas quanto à terminologia adotada por seu colega, Hinshelwood não questiona o raciocínio de Morgan de que se trata de um quadro congênito. Ao contrário, assume a mesma posição para definir em "termos mais científicos" o mesmo "defeito":

Pelo termo cegueira verbal congênita, nós entendemos um defeito congênito que ocorre em crianças com cérebros normais e sem nenhuma outra alteração, caracterizado por uma dificuldade tão grande em aprender a ler que é obviamente (manifestly) devida a uma condição patológica, e as tentativas de ensinar essa criança pelos métodos comuns falham completamente. (HINSHELWOOD, 1917, p. 40) (tradução e grifos da autora).

Vemos que a atribuição do caráter congênito à cegueira verbal é polêmica desde seu surgimento e que a atual discussão sobre a (a)cientificidade da dislexia (como muito enunciada, por exemplo, por Moysés e Collares (1992, 2011), por Coudry e Freire (2005) ou Beà (2011)) já estava presente nos primeiros textos que passaram a postular a sua existência. Beà, por exemplo, depois de resumir diferentes teorias sobre a dislexia, salienta o fato de nenhuma ter sido confirmada (p. 22) e, em embora não negue a existência da dislexia, assume, de forma genérica, que o que acontece com a criança disléxica e com aquelas que têm problemas de aprendizagem é que "em consequência de fatores constitucionais e da relação com seu entorno não chegam a organizar adequadamente sua mente e suas funções psíquicas de forma suficientemente apta para a aprendizagem" (BEÀ, 2011, p. 23). Dois enunciados mais contundentes sobre a "acientificidade" dos diagnósticos de dislexia são o das brasileiras Moysés e Collares: “os 'distúrbios de aprendizagem' são uma construção do pensamento médico, e a hipótese da existência da dislexia é decorrente do já questionável "raciocínio clínico tradicional'" (MOYSÉS e COLLARES, 1992, p. 33) e o do britânico Stringer, conforme relatado por Elliott e Grigorenko:

Em janeiro de 2009, um membro do Parlamento Britânico, Graham Stringer, provocou uma espécie de tempestade internacional ao questionar a validade do conceito de dislexia... Ao descrever dislexia como "uma ficção cruel não mais real do que o construto científico do "éter" no século XIX para explicar como a luz atravessa o vácuo”, ele argumentou que a razão pela

${ }^{6}$ Vale a pena notar que, em duas citações de Hinshelwood, aqui reproduzidas, o autor usou a mesma expressão: "na minha opinião" em textos supostamente científicos: a) "o principal fator que contribuiu para a rápida melhora foi, na minha opinião, a retirada total do álcool" (HINSHELWOOD, 1896, p. 1452) e b) "essa transição de um trabalhador hábil à condição de total desamparo só pode ser compreendida, na minha opinião, pela falha da memória visual” (ibid., p. 1453). 
qual muitas crianças se debatem contra a alfabetização está relacionada ao fato de elas terem falhado por conta do "establishment" da educação. Ao invés de admitir que a instrução pobre foi a culpada, argumentou ele, uma desordem cerebral chamada dislexia foi inventada. (ELLIOTT e GRIGORENKO, 2014, p. 1)

Outra grande semelhança entre os textos fundadores, neste caso, especificamente o de Morgan e os textos atuais sobre dislexia em crianças e adolescentes (para citar alguns: Deuschle e Cechella (2009) e Beà (2011)), está nos exemplos tomados como indicativos da existência de tal defeito congênito. Vejamos, na Figura 1, os erros apontados pelo autor na escrita de um adolescente diagnosticado como portador de cegueira verbal congênita:

In writing his own name he made a mistake, putting "Precy" for "Percy", and he did not notice the mistake until his attention was called to it more than once. I asked him to write the following words:

$\begin{array}{lcl}\text { Song } & \text { he wrote } & \text { scone } \\ \text { Subject } & \text { "، } & \text { scojock } \\ \text { Without } & \text { “ } & \text { wichout } \\ \text { English } & \text { “ } & \text { Englis } \\ \text { Shilling } & \text { “ } & \text { sening } \\ \text { Seashore } & \text { " } & \text { seasow }\end{array}$

Figura 1: Exemplos da escrita de um adolescente (MORGAN, 1896, p. 1378).

Podemos observar diversos "erros" ortográficos: a dificuldade em grafar a coda de sílabas complexas em "per" (no próprio nome), "song" e "sub" substituídas respectivamente por: "pre", "scone" e "sco", a grafia do "c" em vez do "t" em "without"; a ausência do "h" nas palavras "english", "shilling" e "seashore" e a grafia do "n" em vez de "ll".

Bem mais recentemente, em 2011, a médica catalã Beà apresentou a seguinte imagem como representativa de um "grafismo do tipo disléxico":

\footnotetext{
${ }^{7}$ A partir deste momento, insiro aspas em "erros" de "erros ortográficos" para reforçar que não indicam apenas a falta, isto é, o que a criança ou adolescente ainda não sabe sobre a escrita convencional, mas indicam também o que o sujeito que se aproxima da escrita já sabe sobre o sistema alfabético da sua língua. O que é um erro para um adulto leigo deve ser tomado pelo professor alfabetizador como um objeto de análise, pois fornece indícios dos caminhos já trilhados e dos ainda não percorridos no processo de ensino-aprendizagem.
} 


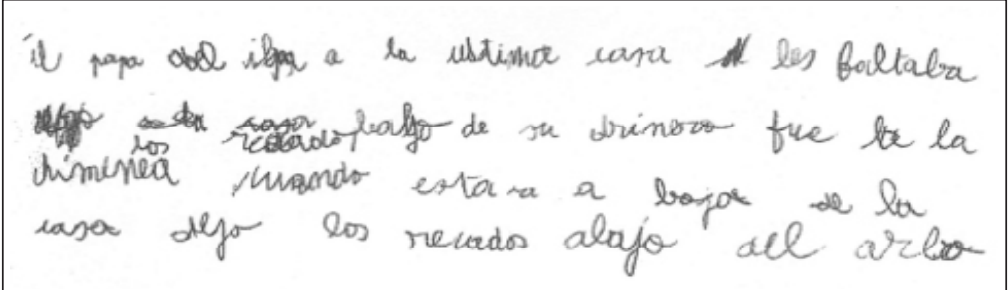

Figura 2: Reprodução do primeiro quadro dos exemplos de "grafismo disléxico" de uma criança espanhola de oito anos (BEÀ, 2011, p. 28).

El papa Noel iba a la ultima casa les faltaba los recados(regalos) bajo? de su drinero fue a la chimenea cuando estava a bajo de la casa dejo los recados abajo del arbo

Figura 3: Transcrição do quadro presente na figura 2 (realizada pela autora).

Podemos observar que as seguintes ocorrências de escrita não convencional estão sendo tomadas como sinais de dislexia: oscilação entre a escrita "a bajo" (segunda linha) e "abajo" (terceira linha); "recados" no lugar de "regalos"; "drinero" no lugar de "dinero"; "estava" no lugar de "estaba"; "arbo" no lugar de "árbol"; falta de acentos (última, dejó e árbol); falta de sinais de pontuação e presença de rasuras.

$\mathrm{Na}$ época em que Morgan escreveu seu texto, "erros" como os apresentados pelo seu paciente ainda não haviam sido objeto de estudo científico. A Linguística sequer havia sido fundada como ciência. A "análise" que o médico oftalmologista fez desses "erros" consiste unicamente na constatação de que aquilo que foi escrito se distancia das formas ortográficas das palavras, o que contribuiria para a caracterização de uma dificuldade tão "notável", tão "pronunciada", conforme afirmação de Morgan (1896, p. 1379), citada anteriormente.

Hoje em dia, porém, a Linguística passou a abordar cientificamente o processo de aquisição da leitura, da escrita e da ortografia. Do ponto de vista de linguistas como Coudry e Scarpa (1985), Abaurre (1992), De Lemos (1995), Possenti (2005) e Coudry e Freire (2005), "erros" ortográficos semelhantes aos apresentados por Morgan podem indicar que o sujeito elabora hipóteses sobre o sistema ortográfico da sua língua e são frequentes ao longo do processo de aquisição da escrita.

A dificuldade em grafar sílabas complexas, por exemplo, é muito comum, conforme afirma Abaurre (2001), já que as crianças em processo de aquisição da ortografia alfabética demonstram dificuldades em preencher a posição de coda silábica ${ }^{8}$. A primeira estrutura adquirida seria a canônica CV (Consoante-Vogal) e a criança crê já ter completado a sílaba a partir do momento em que já escreveu

${ }^{8}$ A estrutura interna das sílabas de "arbol", considerando as propostas de estruturação interna da sílaba (cf. Halle \& Vergnaud, 1978; Selkirk, 1982) utilizada por Abaurre (2001) é a seguinte: $1^{\text {a }}$ sílaba: núcleo e coda; $2^{\mathrm{a}}$ sílaba: ataque, núcleo e coda. A sílaba mais frequente, portanto, é a que contém ataque e núcleo (como as "vo" e "re", se considerarmos a palavra "árvore"). 
uma consoante e uma vogal. No caso do adolescente acompanhado por Morgan, podemos supor que ele percebe a complexidade de algumas sílabas, o que o leva a não optar pela estrutura CV mas, diante disso, opta por registrar essa complexidade sempre no ataque silábico: "scone", "pre" e "sco".

\section{ONDE ESTÁ O AVANÇO DA CIÊNCIA?}

Apesar de a dislexia ser definida como dificuldade de leitura e/ou de escrita ${ }^{9}$, continua a ser analisada com a mesma perspectiva leiga de 1896. Sem uma análise adequada, passa a ser tratada por profissionais que costumam fazer parte das chamadas "equipes multidisciplinares" que não incluem reflexões desenvolvidas no âmbito da linguística.

Críticas à desconsideração dos saberes da Linguística não são recentes. Já estavam presentes em Jakobson ([1963]2010), quando o autor se referia às afasias:

Um livro recente, por exemplo, que trata extensamente das complexas e múltiplas implicações da afasia infantil, faz um apelo em prol da coordenação de várias disciplinas e reclama a cooperação de otorrinolaringologistas, pediatras, audiólogos, psiquiatras e educadores; todavia, a ciência da linguagem ainda passa em silêncio como se as perturbações da percepção da fala não tivessem nada a ver com a linguagem. Esta omissão é tanto mais deplorável na medida em que o autor é o diretor da clínica de audição e afasia infantil da North Western University, que tem, entre seus linguistas Werner F. Leopold, sem dúvida o melhor especialista norte-americano em linguagem infantil (JAKOBSON, [1963]2010, p. 43, grifos da autora).

Fora do âmbito da Linguística, é muito frequente que se tomem "erros" ortográficos equivalentes aos do paciente de Morgan não apenas como indícios, mas como evidência da existência da dislexia. Na prática, é comum que "erros" dessa natureza sejam o que justifique o diagnóstico, sem qualquer análise sobre o processo escolar pelo qual a criança ou o adolescente teria passado. Ainda que costume haver referências às dificuldades de adaptação à escola ou a diferentes professores, por exemplo, essas questões, provavelmente por serem consideradas subjetivas, não são aprofundadas e perdem a relevância quando comparadas aos "erros" ortográficos - tomados como uma espécie de registro científico que evidenciaria o distúrbio, o déficit.

É comum ouvir diferentes profissionais afirmarem que determinada criança tem dislexia porque "troca surdas por sonoras". O relato de uma estagiária em

\footnotetext{
${ }^{9}$ A definição de dislexia, desde sempre, tem flutuado. O próprio Morgan a havia definido como dificuldade para ler, mas comprova essa dificuldade com erros de ortografia, segmentação e pontuação. No site da ABD (Associação brasileira de dislexia), consta a seguinte definição "A Dislexia do desenvolvimento é considerada um transtorno específico de aprendizagem de origem neurobiológica, caracterizada por dificuldade no reconhecimento preciso e/ou fluente da palavra, na habilidade de decodificação e em soletração. Essas dificuldades normalmente resultam de um déficit no componente fonológico da linguagem e são inesperadas em relação à idade e outras habilidades cognitivas. (Definição adotada pela IDA - International Dyslexia Association, em 2002”. Disponível em < $\underline{\text { http:// }}$ www.dislexia.org.br/o-que-e-dislexia/> . Acesso em 26 de dezembro de 2017.
} 
Fonoaudiologia, analisado por Aquino (2016, p.121) indica que isso ocorre e que ela está atenta a essa questão:

A gente estudou que os erros de aquisição da ortografia são comuns, que troca de surda por sonora não é sintoma de dislexia, mas tem muita criança encaminhada pra cá por causa disso. A escola deveria saber que isso não é motivo. (Estagiária de Fonoaudiologia, em entrevista concedida a Aquino em junho de 2015).

A estagiária cursou na Universidade Estadual de Campinas, que prevê disciplinas obrigatórias no Instituto de Estudos da Linguagem, onde aprendeu que a oscilação na representação do traço da sonoridade não pode ser considerada como sintoma de distúrbio algum, pois tal fenômeno é bastante comum durante o processo típico de aquisição da escrita. Alguns autores, como Cagliari ([1989] 2000), afirmam que isso decorre do fato de a criança sussurrar antes de escrever a letra correspondente e, com o sussurro, perder o único traço distintivo entre pares como [f] e [v], [t] e [d], [s] e [z] - o vozeamento. Ao sussurrar a palavra "vaca" ['vake], por exemplo, tem-se como resultado a palavra "faca" ['fake] e, por isso, muitas crianças ficam sem saber quando usar "f" ou " $v$ ". Sem que um adulto aponte o que está levando a essa confusão, as crianças não sabem quando devem escrever uma consoante ou outra e, então, "chutam" (ora uma consoante, ora outra) para representar o fone que ouvem quando sussurram para si antes de escrever.

Outros "erros" são ocasionados pelas relações que as crianças estabelecem entre a escrita e os nomes das letras, como podemos ver em um dado de MF - uma criança de 10 anos que acompanhei no Centro de Convivência de Linguagens $\left(\right.$ CCazinho) ${ }^{10}$. Durante o mês de maio de 2014 - mês que antecedeu à copa do mundo de futebol - realizamos atividades de leitura e de escrita sobre o tema, já que MF gosta de esportes. Diante da tabela com as seleções divididas em seus respectivos grupos, perguntei a MF onde estava escrito "Grécia" e ele apontou para "Holanda". Ao perceber minha surpresa, apontou depois para "Honduras". O que para um leigo pode indiciar um "erro" decorre de um raciocínio singular. Ao entender que teria que localizar a palavra "Grécia", MF foi em busca de palavras iniciadas pela letra que ele julgava representar o fone [g], e, tomando por base o nome das letras, encontrou o "h". O que se poderia julgar como "absurdo" passa a indiciar uma lógica, já que "h" é a única letra do nosso alfabeto cujo nome "agá" [a'ga] contém o fone [g] e a letra "g" - que nós, adultos já alfabetizados, sabemos ser a letra inicial da palavra ['gResic] - tem o nome "gê" ['ze]. Para MF, "g", por

${ }^{10}$ O CCazinho (Centro de Convivência de Linguagens) é, como o nome indica, um centro de convivência entre crianças e professores e estudantes da Unicamp, e "tem como objetivo acompanhar e intervir, com base na perspectiva teórica e metodológica elaborada pela Neurolinguística Discursiva, no processo de aquisição da leitura e da escrita de crianças que receberam diagnósticos como: Transtorno do Déficit de Atenção com ou sem Hiperatividade (TDAH), Dislexia, Alteração no Processamento Auditivo e Distúrbio de Aprendizagem - que não se confirmam ao longo dos acompanhamentos longitudinais". Funciona também como "uma das fontes de dados e de pesquisas do Projeto Integrado em Neurolinguística: práticas com a linguagem e documentação de dados (coordenado pela Profa. Dra. Maria Irma Hadler) ativo desde agosto de 1992 e renovado em 2009 - processo: 307227/2009-0. Aprovado pelo Comitê de Ética em Pesquisa da Faculdade de Ciências Médicas da UNICAMP (CEP: 326/2008)" (COUDRY, 2017). 
ter esse nome, poderia estar presente no início de "Japão", mas não de Grécia. Quando conversamos sobre suas hipóteses, MF disse que "achava que a letra "g" só tinha o som de [3]". Ainda a respeito do "h", cabe uma observação que nos leva a compreender melhor a associação feita por MF; se [a'ga] fosse o nome da letra "g", não seria o único caso do alfabeto em que a letra que representa o fone consonantal correspondente aparece entre duas vogais; temos os casos de $\mathrm{f}=\left[{ }^{\prime} \varepsilon \mathrm{fI}\right]$, $1=\left[{ }^{\prime} \varepsilon l \mathrm{I}\right], \mathrm{m}=$ ['emI $], \mathrm{n}=$ ['enI $], \mathrm{r}=$ ['exI $]$ e $\mathrm{s}=$ ['esI $]$; o fato de ele ter suposto que essa regularidade poderia ocorrer não só com palavras compostas pelas vogais [e] e $[\varepsilon]$, mas também com o [a] ( $\mathrm{g}=$ [a'ga]) é plenamente justificável para alguém que se depara com um universo que, apesar de uma grande regularidade, tem letras cujos nomes são "jota", "xis", “dáblio" e "ípsilon”.

Sem um conhecimento desse tipo, as consequências podem - e têm sido gravíssimas. MF, por exemplo, foi diagnosticado com déficit cognitivo, segundo o laudo que o acompanhava quando chegou ao CCazinho. A mesma criança que, em cerca de sete meses de acompanhamento, passou a ler todas as palavras com as quais se deparava, embora ainda lesse sílaba a sílaba para só então retomar a palavra que tinha acabado de ler, pronunciando-a na sua totalidade. No nosso último encontro, em novembro de 2015, propus a leitura de um manual com as regras do jogo "paintball"11 e, assim que apresentei o texto, ele tentou "negociar" a leitura; queria que eu lesse algumas palavras enquanto ele leria outras, de preferência as menores (uma estratégia recorrente nos nossos encontros). Começamos intercalando a leitura, mas, assim que ele se deu conta do conteúdo do texto, continuou a ler sozinho. Leu, compreendeu, comentou as diferenças das regras e da nomenclatura em relação ao jogo que ele está acostumado a jogar em Campinas. Em resumo: "aprendeu a ler"12.

Análises como as feitas durante o acompanhamento de $\mathrm{MF}$ a respeito de quais hipóteses ele faz sobre a escrita de algumas palavras e que parecem "erros" aparentemente absurdos são cruciais - como insistem os linguistas que estudam a aquisição de linguagem escrita - para que o pesquisador/adulto/professor procure entender quais representações a criança está construindo ao longo do processo. Isso demanda funcionamentos complexos e integrados de todo o cérebro toda a vez que está em jogo a representação escrita (Coudry e Freire, 2005). Seria eficaz que a criança recebesse respostas dos adultos ajustadas às hipóteses que está elaborando para ajudá-la a compreender o sistema de escrita alfabético, que não é lógico.

Em vez disso, vemos proliferar propostas para a "resolução do problema" sem respaldo - nem teórico, nem empírico - como a apresentada a seguir - o "Método das boquinhas", que recebeu atenção especial neste trabalho por ser cada vez mais difundido na alfabetização de crianças.

${ }^{11}$ Esse trecho do manual incluía as regras do paintball em um campeonato em Portugal adaptadas por mim para o português do Brasil.

${ }^{12} \mathrm{O}$ acompanhamento de MF terminou em novembro de 2015, pois, em 2016, ele mudou de escola e passou a estudar à tarde, período coincidente com as reuniões do CCazinho. Em março de 2016, sua mãe enviou uma mensagem em que escreveu: "Ele está com bastante incentivo e animado, teve provas adaptadas e tirou 8 e 9 . Está super feliz." 


\section{O MÉTODO DAS BOQUINHAS: UMA ANÁLISE CRÍTICA}

Vejamos o que acontece a partir do uso do "Método das boquinhas", desenvolvido por Jardini (2003). Do item "Fundamentação teórica", que acompanha o método, selecionamos o seguinte trecho, que visa explicitar seu objetivo e seu ponto de partida teórico-metodológico:

O Método Fonovisuoarticulatório, carinhosamente apelidado de Método das Boquinhas, utiliza-se além das estratégias fônicas (fonema/som) e visuais(grafema/letra), as articulatórias (articulema/Boquinhas). Seu desenvolvimento foi alicerçado na Fonoaudiologia, em parceria com a Pedagogia, que o sustenta, sendo indicado para alfabetizar quaisquer crianças e mediar/ reabilitar os distúrbios da leitura e escrita" (...) Os autores Heilman, Voeller e Alexander (1996) afirmam que para a automatização da conversão fonema/grafema, é preciso ativação do gesto motor articulatório, reiterado por Santos (2009). (Jardini, $\left(2003^{13}\right.$ grifos da autora).

O material contém um espelho para cada criança olhar sua própria boca enquanto pronuncia cada fone e comparar a conformação da sua boca com a da figura, disposta em uma carta, que mostra a articulação desse mesmo fone, bem como a representação gráfica da letra à qual o fone corresponde.

Em cursos de capacitação, professores alfabetizadores têm tido acesso a vídeos do "Método das boquinhas" elaborados por Jardini, Esses vídeos não estão disponíveis, nem mesmo no site do "Método das boquinhas", pois são específicos para os cursos. Porém, em dezembro de 2012, Senna publicou um desses vídeos, intitulado "Consoantes - Método das Boquinhas. ${ }^{14}$

Nesse vídeo, uma mulher, seguindo a ordem das letras correspondentes às consoantes do nosso alfabeto, pronuncia não o nome da letra, mas um (e apenas um) dos fones que ela representa (geralmente com a vogal [e]) e, na sequência, algumas palavras que contêm o fone pronunciado. Isso não acarreta nenhum problema em relação a algumas consoantes, por exemplo o "p" que, praticamente, não sofre variação e representa, sempre, um único fone, $o[p]^{15}$. Já na segunda consoante do alfabeto, porém, começam os problemas.

${ }^{13}$ Disponível em http://www.metododasboquinhas.com.br/Fundamenta\% C3\%A7\%C3\%A3o Te\%C3\% B3 rica2.aspx, acesso em 23 de agosto de 2015.

${ }^{14}$ Foigraçasà postagem de Sennano endereço https://www.youtube.com/watch?v=Dx4XHtNy9n8 que tivemos acesso a esse vídeo. Embora Jardini, criadora do método e do vídeo, tenha publicado, em 2015, um comentário criticando a sua divulgação sem os devidos créditos, ele permanece disponível no Youtube. Em junho de 2017, o vídeo contava com 131.480 visualizações e em dezembro do mesmo ano com 190.572 .

${ }^{15}$ Afirmamos que essas consoantes "praticamente" não sofrem variação porque apresentam diferenças articulatórias, correspondentes à sua coarticulação com a vogal seguinte. Mesmo quando houver um [r] ou um [1] entre uma consoante e a vogal seguinte, os lábios e a língua adquirem a conformação da vogal já no momento da produção da oclusiva. $O$ fenômeno da coarticulação foi reportado, por exemplo, por Öhman (1966) e, no Brasil, por Silva (1996). Caso o leitor queira conferir empiricamente o fenômeno, pode pensar em pronunciar (apenas "com a boca", sem emitir sons) a sílaba "pi" e, depois, a sílaba "pu". Se fizer esse exercício, certamente perceberá como a boca já assume a conformação da vogal antes mesmo da produção da consoante oclusiva. 


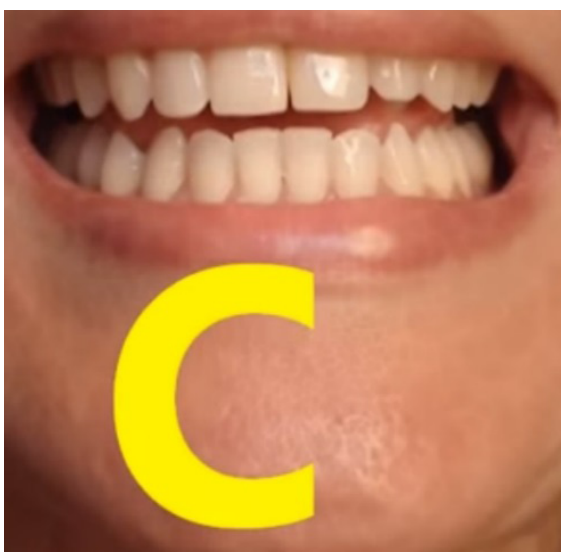

Figura 4: Tela do vídeo representando a pronúncia do fone correspondente à letra "c".

Embora estejamos diante da letra "c" na tela, a professora está pronunciando a sílaba [ki], presente na palavra "máquina". Assim que apareceu o "c" no vídeo, ela pronunciou [kə] e, com uma hiperarticulação de todas as sílabas, as seguintes palavras: "casa", "máquina", "macaco". A mesma lógica foi utilizada em relação a outras letras (por exemplo, diante da letra "x", ela pronunciou "chapéu", "cachimbo", "caixa"; diante de "z", "zebra", "cozinha", "mesa"). As únicas referências à possibilidade de um mesmo fone ser representado por mais de uma letra são as ilustradas nas figuras 5, 6 e 8. Na figura 7, inversamente, é ilustrada uma letra que pode ser pronunciada por dois diferentes fones.

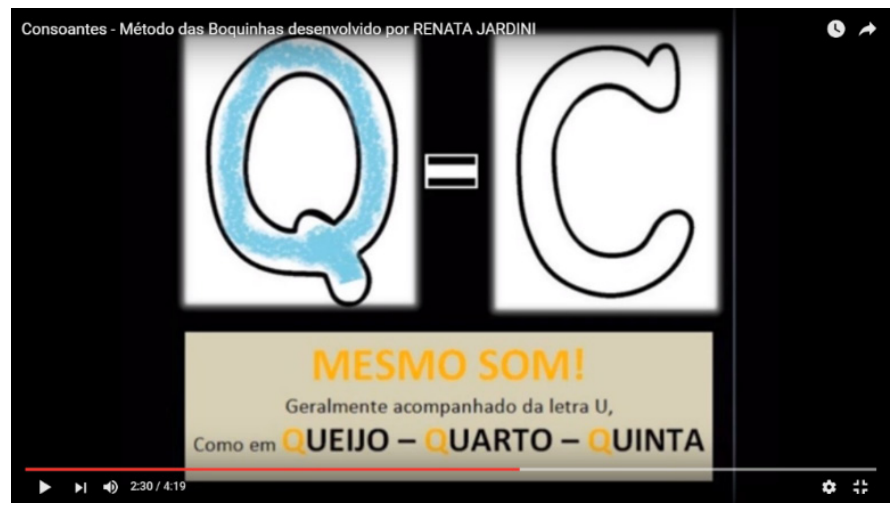

Figura 5: Tela do vídeo representando a pronúncia do fone correspondente às letras "q" e "c". 


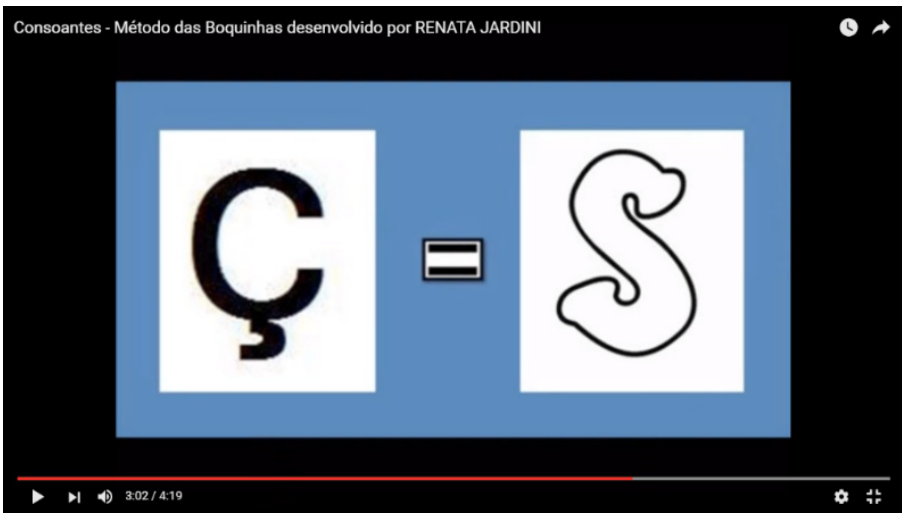

Figura 6: Tela do vídeo representando a pronúncia do fone correspondente às letras "ç" e "s".

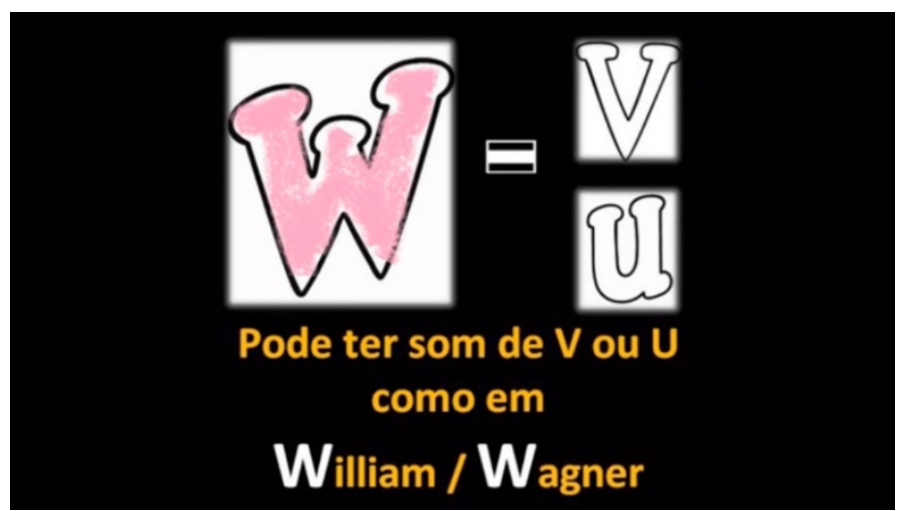

Figura 7: Tela do vídeo representando as pronúncias dos fones correspondentes à letra "w".

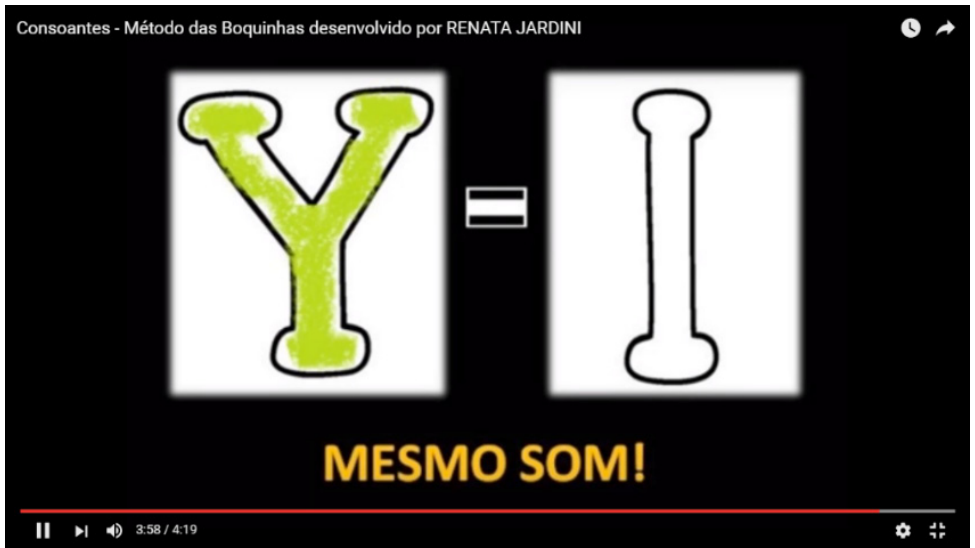

Figura 8: Tela do vídeo representando a pronúncia do fone correspondente à letra "Y". 
"X", a consoante que mais fones pode representar na língua portuguesa ([s], $\left.[\mathrm{z}],\left[\int\right],[\mathrm{ks}]\right)$, não recebeu o mesmo destaque dado às consoantes anteriores. Outro equívoco do método é a equivalência sonora entre "q" e "c" que desconsidera que "c" pode representar o som de "s" no início de palavras e também de "ss" em outros contextos no meio das palavras. Além disso, o texto da parte inferior da figura 5 contém um erro sobre o sistema ortográfico da língua portuguesa: o "q" não vem "geralmente acompanhado da letra u". Na escrita, a não ser em raros casos de abreviações (por exemplo, "q" (abreviação de "que") ou "pq" (abreviação de "porque"), "Abrinq" (sigla da Associação Brasileira dos Fabricantes de Brinquedos)), ele não aparece sem ela.

Podemos questionar se uma criança ainda não alfabetizada - que não sabe, portanto, que as palavras "chapéu" e "cachimbo" devem ser escritas com "ch" e que "mesa" não se escreve com "z", mas com "s" - vai aprender a escrever essas palavras com a ortografia convencional por meio desse método e como isso pode influenciar "erros" ortográficos e, consequentemente, diagnósticos atribuídos às crianças.

Preocupa o fato de que esse tipo de material, com equívocos como os já apontados, oriente a ação pedagógica nos processos de alfabetização. Como mostra a Figura 9, os professores estão sendo convidados a divulgar a sua experiência e a contribuir para a difusão do método:
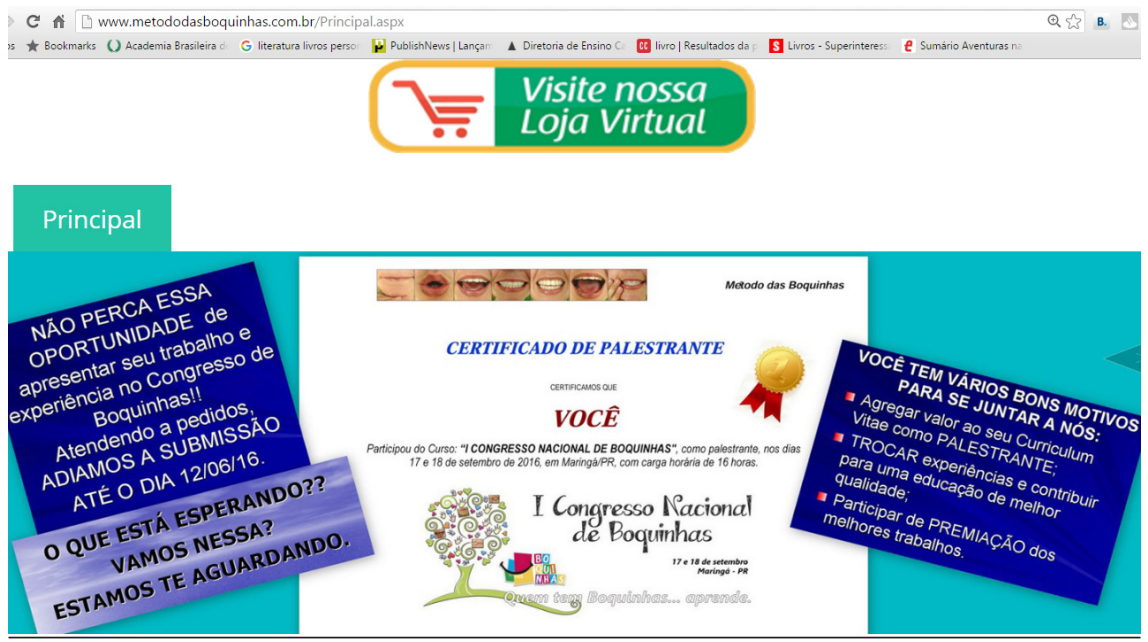

Figura 9: Página do site “Método das boquinhas”, de Jardini. Acesso em 04 de junho de 2016.

Vale a pena destacar o fato de que, na propaganda do I Congresso Nacional de Boquinhas, o certificado oferecido não é o de participante, mas o de palestrante, sem que haja qualquer menção aos requisitos necessários para tal.

Iniciativas que partem de equívocos sobre as relações fônico-gráficas e que se propõem a lidar com a alfabetização não são exclusividade desse método. Também em outras áreas há profissionais que se apresentam como especialistas no 
tratamento de diferentes "déficits escolares" e que dão mostras de uma formação precária no que diz respeito aos processos de leitura e escrita.

Vejamos dois relatos equivocados do ponto de vista linguístico, sobre intervenções para sanar as dificuldades das crianças consideradas disléxicas:

Eu peço pra ele olhar bem na minha boca, pra ver como eu pronuncio os sons [pe] e [be] pra que ele perceba a diferença e não troque mais as letras, mas não adianta, ele continua trocando. (Professora alfabetizadora, em entrevista concedida a Aquino em junho de 2015).

No final deste mês de junho corrente será lançada a primeira cartilha nacional especialmente desenvolvida para crianças disléxicas, batizada de "Facilitando a Alfabetização". Ela é baseada em materiais criados pela Sociedade Internacional de Dislexia, com sede nos Estados Unidos. A cartilha oferece exercícios que combatem as principais dificuldades enfrentadas pelos disléxicos como, por exemplo: Ao ouvirem o som do "F" os disléxicos escrevem "V", a cartilha mostra ilustrações do movimento dos lábios para que os disléxicos "leiam" o fonema correto que está sendo pronunciado pelo interlocutor (Veloso, Estabille e Aguilera, s/d) ${ }^{16}$

Ambos os exemplos desconsideram o fato de que cada par consonantal [p]/ [b] e $[\mathrm{f}] /[\mathrm{v}]$ tem o mesmo modo e o mesmo ponto de articulação. No caso do primeiro par, ambas são oclusivas bilabiais, o que significa que a criança sempre vê os mesmos gestos articulatórios (o que pode ser conferido no espelho): os lábios inicialmente estendidos (considerando-se que estão precedidos pela vogal [e]) e cerrados, seguidos de sua abertura abrupta, após a qual, a depender da intensidade da articulação promovida pelo falante, vê-se também a língua na conformação da vogal [e], além dos dentes. Ou seja, é impossível diferenciar esse par ([p]/[b]) ou os demais pares de consoante surda/consoante sonora, por meio da observação visual dos gestos fonatórios.

Sem o conhecimento desses fenômenos (o que implica um saber técnico produzido pela Linguística e sua verificação empírica, o déficit é atribuído à criança que não percebe essas diferenças visualmente e nunca as perceberá, pois são inexistentes. O único traço que distingue pares como $[\mathrm{p}] /[\mathrm{b}],[\mathrm{t}] /[\mathrm{d}],[\mathrm{k}] /[\mathrm{g}]$ e $[\mathrm{f}] /[\mathrm{v}]$ é o "vozeamento", presente nas consoantes sonoras (ou vozeadas) e ausente nas consoantes surdas (ou desvozeadas), traço imperceptível pela visão, mas facilmente identificado com o apoio do tato. Basta colocar uma das mãos no pescoço (próximo às pregas vocais) e produzir cada consoante, fazendo o esforço para não pronunciar uma vogal. Afinal, qualquer vogal é sonora/vozeada e sua produção provocaria uma interferência na percepção tátil da consoante. Para evitar essa interferência, os pares das consoantes fricativas são os mais indicados para essa percepção, pois, diferentemente das demais, é possível pronunciá-las mesmo na ausência de uma vogal. Caso persista a dificuldade para perceber a diferença em relação aos pares consonantais oclusivos ou africados, é fundamental o auxílio do professor para que a criança observe, nas consoantes surdas (por exemplo, o [p], o [t] e o [k]), a ausência do esforço que acompanha a vibração no início da produção das consoantes sonoras (por exemplo, o [b], o [d] e o [g]). É necessário

${ }^{16}$ Material produzido por estudantes da FACCAR, em co-autoria com a orientadora do trabalho, disponível em http://www.faccar.com.br/eventos/desletras/hist/2006g/textos/012.htm, acesso em 08 de outubro de 2014. 
observar exatamente o início (quando a boca ainda está fechada, se considerarmos $\mathrm{o}$ [p] e o [b]), já que a produção efetiva da consoante só ocorrerá em conjunto com a vogal e, nesse momento, haverá o vozeamento obrigatório para a produção da vogal.

Essas estratégias somadas à compreensão de que as crianças, ao sussurrar as palavras antes de escrevê-las, apagam seu traço de sonoridade, poderiam ser úteis para professores alfabetizadores e, eventualmente, poderiam evitar uma grande quantidade de encaminhamentos desnecessários para a clínica.

\section{QUAL A SAÍDA?}

As reflexões desenvolvidas no âmbito da ND têm permitido aos profissionais das áreas de Linguagem, Educação e Fonoaudiologia, especialmente àqueles que têm a oportunidade de vivenciar um ambiente como o CCAzinho, não apenas questionar afirmações como as que foram discutidas neste trabalho principalmente relativas às relações entre a fala e a escrita - mas também inferir sobre quais hipóteses as crianças constroem durante os processos de aquisição da leitura e da escrita. A experiência com o acompanhamento de MF nesse ambiente me possibilitou acompanhar de perto esses processos.

Falta, a meu ver, a muitos cursos de Fonoaudiologia, de Pedagogia de Psicopedagogia e mesmo de Letras um conhecimento técnico para que os profissionais exerçam suas atividades de forma responsável, como aponta Coudry (2017).

O que vejo como um elemento a ser também problematizado é o fato de a escola - a instituição encarregada da alfabetização - não estar preparada e/ou não ter condições adequadas para sanar as dificuldades (previsíveis, faço questão de reforçar, pois intrínsecas ao processo) no momento em que elas aparecem e, com isso, permitir que se transformem em um problema de grandes proporções, o que leva muitas crianças a desistirem da leitura e da escrita, por não compreenderem o sistema.

Sem apoio escolar adequado, muitas dessas crianças passam a peregrinar por consultórios com profissionais que - assim como grande parte dos professores alfabetizadores - também não receberam formação adequada ${ }^{17}$ para analisar as hipóteses que as crianças fizeram sobre a escrita alfabética. Consequência disso

\footnotetext{
${ }^{17}$ Faço a questão de afirmar que não é o professor alfabetizador o responsável pela má formação que recebeu. A meu ver, os currículos dos cursos de Pedagogia e de Letras deveriam ser revistos, de forma a garantir o oferecimento de disciplinas específicas de aquisição da linguagem escrita, a serem ministradas obrigatoriamente por especialistas na matéria. Eu mesma não teria construído o conhecimento no qual me baseio para fazer a presente crítica caso não tivesse tido contato com professores e obras que possibilitaram que eu aprendesse a analisar com o devido embasamento linguístico os chamados erros e acertos das crianças. Esse contato não teve início nas minhas disciplinas obrigatórias do curso de Letras e isso, que considero uma lacuna, tem contribuído para uma formação precária dos profissionais envolvidos com a alfabetização.
} 
é que o problema passa a ser de responsabilidade exclusiva da criança. Apenas algumas "condenadas ao diagnóstico" escapam dele, conforme Oliveira:

No entanto, a teimosia dos pais, responsáveis e professores espalhados pelo mundo, deixava sempre dúvidas nas condenações, pois alguns dos alunos ciosamente diagnosticados pela ciência, às vezes aprendiam. Como seria possível? Seriam eles as exceções que confirmavam as regras? Onde estariam as falhas dos experimentos? Evidenciando a rebeldia do cotidiano (Oliveira 2003), experiências pedagógicas diferenciadas faziam aprender, asseguravam o direito à educação e à dignidade de alguns desses excluídos. OLIVEIRA (COLLARES, MOYSÉS e RIBEIRO, 2013, pp. 80-81).

Crianças que têm a oportunidade de frequentar um lugar como o CCazinho e, como MF, desenvolvem a leitura e a escrita, se beneficiam de um trabalho linguisticamente orientado. Infelizmente, porém, a maior parte das crianças só são encaminhadas a esses espaços depois de terem recebido diagnósticos e rótulos que marcaram seus percursos. Talvez a etapa mais difícil do trabalho com elas seja a de fazê-las acreditar que, apesar de tudo o que já lhes foi dito, elas são, sim, capazes de ler e de escrever.

Essa proposta está fundamentada no trabalho desenvolvido há mais de 30 anos por Coudry e apresentada inicialmente no "Diário de Narciso", obra extremamente atual e que continua inspirando pesquisadores, na qual a autora denuncia os equívocos nas abordagens das afasias - tanto na avaliação, quanto no acompanhamento - o que vale para outras práticas com a linguagem, inclusive as escolares.

\section{REFERÊNCIAS}

ABAURRE, M. B. M. Dados da escrita inicial: indícios de construção da hierarquia de constituintes silábicos? In: HERNANDORENA, C.L.M. Aquisição de língua materna e de língua estrangeira: aspectos fonético-fonológicos. Pelotas: EDUCAT/ALAB, 2001. p. 63-85.

ABAURRE, M. B. M., FIAD, R. S. e MAYRINK-SABINSON, M. L. Cenas de aquisição da escrita: o sujeito e o trabalho com o texto. Campinas - SP: Mercado de Letras: Associação de Leitura do Brasil - ALB, 1997.

AJURIAGUERRA, J. A dislexia em questão: dificuldades e fracassos na aprendizagem da língua escrita. Porto Alegre: Artes Médicas, 1984.

AQUINO, P. A. Polêmica em torno de dislexia: um caso de interincompreensão. Tese de doutorado em Linguística, Universidade Estadual de Campinas, 2016.

BEÀ, E. T. de. Dislexia: una comprensión de los trastornos de aprendizaje. Barcelona: Octaedro, 2011.

BERGER, E. Les maladies des yeux, 1982. Disponível em <https://archive.org/details/ lesmaladiesdesye00berg $>$. Acesso em: 11 de março de 2014.

CAGLIARI, L. C. [1989]. Alfabetização e lingüistica. 10ª ed. São Paulo, SP: Scipione, 2000. 
COUDRY, M. I. H. Neurolinguística Discursiva: afasia e infância. Encontro possível/inevitável. Relatório de Pesquisa CNPq, período: 03/2014 a 03/2017, abril/maio de 2017.

COUDRY, M. I. H. [1986]. Diário de Narciso: Discurso e afasia. São Paulo, SP: Martins Fontes, 1988.

COUDRY, M. I. H. O que é o dado em neurolingüística? In: CASTRO, M. F. P.(Org).

COUDRY, M. I. H. O método e o dado no estudo da linguagem. Campinas: Ed. da Unicamp, 1996.

COUDRY, M. I. H. e SCARPA, E. M. De como a avaliação de linguagem contribui para inaugurar ou sistematizar o déficit. In: GARCIA, A. L., CUNHA, M. C. E ROJO, R. H. R. (Orgs.). Cadernos de distúrbios de comunicação. Série Linguagem, n. 2, 1985.

COUDRY, M. I. H. e FREIRE, M. F. P. O trabalho do cérebro e da linguagem: a vida e a sala de aula. In: Linguagem e Letramento em foco. Cefiel/IEL/Unicamp, 2005-2010.

DE LEMOS, C. T. G. Sobre a aquisição da escrita: algumas questões. In: ROJO, R. (Org.) Alfabetização e letramento. Campinas, SP: Mercado das Letras, 1995. p. 7-17.

DEUSCHLE, V. P \& CECHELLA, C. O déficit em consciência fonológica e sua relação com a dislexia: diagnóstico e intervenção. Revista CEFAC, 2009; 11(Supl2): pp 194-200.

ELLIOTT, J.G., GRIGORENKO, E.L. The dyslexia debate. Cambridge University Press, 2014.

HINSHELWOOD, J. Congenital word-blindness. London: H.K.Lewis \& Co. LTD., 1917.

HINSHELWOOD, J. [1896] Letter- word- and mind-blindness. London, 1900. Disponível em: < https://archive.org/details/letterwordmindbl00hinsuoft $>$. Acesso em: 15 de novembro de 2015.

JAKOBSON, R. [1963] Linguística e comunicação. 22a ed. São Paulo: Cultrix, 2010.

JARDINI, R. S. R. Método das boquinhas: alfabetização e reabilitação dos distúrbios da leitura e escrita. São Paulo: Casa do Psicólogo, 2003. (Livro 1, fundamentação teórica).

MORGAN, M. B. W. P. A case of congenital word blindness. In: Congenital word blindness, The British medical journal, November, 7th, 1896.

MOYSÉS, M. A. A. e COLLARES, C. A. L. "A história não contada dos distúrbios de aprendizagem". In: Caderno CEDES 28: O sucesso escolar: um desafio pedagógico. Campinas: Papirus, 1992.

ÖHMAN, S Coarticulation in VCV Utterances: Spectrographic Measurements. Journal Acoustical Society America. 1966 Jan;39(1):151-68.

OLIVEIRA, I. B. O conhecimento na era dos transtornos: limites e possibilidades, In: COLLARES, C. A. L, MOYSÉS, M. A. A \& RIBEIRO, M. C. F. (Orgs.) Novas capturas, antigos diagnósticos na era dos transtornos. Campinas: Mercado de Letras, 2013.

POSSENTI, S. Aprendendo a escrever (re)escrevendo: Linguagem e Letramento em foco língua Portuguesa. 2005 - 2010.

SILVA, A. H. P. Para a descrição fonético-acústica das líquidas no português brasileiro: dados de um informante paulistano. Dissertação de Mestrado em Linguística, Universidade Estadual de Campinas; 1996. 